\title{
Does titration of mitomycin $C$ as an adjunct to trabeculectomy significantly influence the intraocular pressure outcome?
}

\author{
Susan J Lee' \\ Augusto Paranhos ${ }^{2}$ \\ M Bruce Shields' \\ 'Department of Ophthalmology \\ and Visual Science, Yale University \\ School of Medicine, New Haven, \\ Connecticut, USA; ${ }^{2}$ Federal University \\ of São Paulo, São Paulo, Brazil
}

\begin{abstract}
Purpose: To evaluate the benefit of titrating the concentration and exposure time of mitomycin $\mathrm{C}$ (MMC) as an adjunct to trabeculectomy.

Methods: This report consists of a retrospective study and a review of the literature. In the study, consecutive glaucoma patients were evaluated who underwent trabeculectomy with adjunctive MMC that was titrated for concentration and exposure time, based on patient's risk factors for surgical failure. After minimum follow-up of 6 months, patients were divided into success (intraocular pressure $7-17 \mathrm{mmHg}$ ), hypertension $(>17 \mathrm{mmHg}$ ) and hypotony $(<7 \mathrm{mmHg}$ ) groups, which were compared with regard to MMC protocol and patient variables. The literature review included reports of trabeculectomy and adjunctive MMC with and without titration.
\end{abstract}

Results: One hundred and fifty-five eyes of 155 patients were studied. There were no significant differences between the three outcome groups and MMC protocol $(\mathrm{p}>0.05)$. The only significant patient variable was older age in the hypotony group $(\mathrm{p}=0.009)$. The literature is conflicting regarding the value of titrating $\mathrm{MMC}$ as an adjunct in trabeculectomy.

Conclusion: The outcome of trabeculectomy with adjunctive MMC appears to represent a complex interaction of patient and surgical variables. While there is some support for a benefit of titrating MMC according to individual patient variables, there is inadequate evidence at the present time to claim superiority for any MMC protocol, with or without titration.

Keywords: glaucoma surgery, trabeculectomy, mitomycin C, intraocular pressure
Correspondence: M Bruce Shields Yale Eye Center, 40 Temple Street, Third Floor, New Haven, CT 065 10-27I5, USA $\mathrm{Tel}+\mathrm{I}$ 203-785-6288

Fax +I 203-785-7694

Email bruce.shields@yale.edu
The introduction of mitomycin C (MMC) as an adjunct to trabeculectomy was a major advance in our ability to improve the intraocular pressure (IOP) lowering efficacy of the procedure. ${ }^{1-7}$ With it, however, came an increased risk of serious complications, including hypotony maculopathy in the early postoperative course. Many investigators have attempted to find protocols for the adjunctive therapy that will provide an acceptable balance between the benefits and risks.

The two MMC variables that have been evaluated most extensively are drug concentration and duration of application. Some surgeons have reported good results with a fixed concentration/duration protocol for all patients, ${ }^{1-9}$ while others have attempted to improve the outcome by titrating either concentration or duration according to each patient's risk for surgical failure. ${ }^{10-16}$ To date, there has been no compelling evidence to support the superiority of one MMC protocol over another.

The purpose of this paper is to evaluate the benefit of titrating MMC as an adjunct to trabeculectomy, based on a review of the literature and a retrospective analysis of our experience with titrating both concentration and duration of MMC in a series of patients undergoing trabeculectomy. 


\section{Patients and methods}

The medical records of a series of patients who underwent trabeculectomy with adjunctive MMC, performed at the Yale Eye Center by one surgeon (MBS), were retrospectively reviewed. The study protocol followed the guidelines of the Helsinki Declaration and was approved by the local ethics committee. For patients that underwent surgery in both eyes, one eye was randomly selected by coin toss for inclusion in the study. Concentration $(0.2,0.3$, or $0.4 \mathrm{mg} / \mathrm{ml})$ and exposure time (1-5 minutes) of MMC for each patient were determined according to a protocol based on risk factors for excessive postoperative fibrosis (Table 1). Each risk factor was assigned a score, based on past experience, the sum of which was used to determine the protocol for MMC. In some patients, the duration of MMC exposure was modified at the time of surgery based on the extent of scar tissue, bleeding, and thickness of Tenon's capsule.

Table I Protocol for the concentration and exposure time of mitomycin $\mathrm{C}$ during trabeculectomy based on risk factors for excessive postoperative fibrosis

\begin{tabular}{|c|c|c|}
\hline \multicolumn{2}{|c|}{ Risk factors } & Value \\
\hline \multicolumn{2}{|c|}{ Age: less than 10 years } & 3 \\
\hline \multicolumn{2}{|c|}{ Age: $10-25$ years } & 2 \\
\hline \multicolumn{2}{|c|}{ Age: $25-40$ years } & 1 \\
\hline \multicolumn{2}{|c|}{ Age: greater than 70 years } & -1 \\
\hline \multicolumn{2}{|l|}{ Black } & 1 \\
\hline \multicolumn{2}{|c|}{ Sturge-Weber syndrome } & 2 \\
\hline \multicolumn{2}{|c|}{ Uveitis - inactive } & 2 \\
\hline \multicolumn{2}{|c|}{ Uveitis - active } & 4 \\
\hline \multicolumn{2}{|c|}{ Neovascular glaucoma } & 4 \\
\hline \multicolumn{2}{|c|}{ Repeat filtration (I trab/no antimetabolites) $)^{\S}$} & 2 \\
\hline \multicolumn{2}{|c|}{ Repeat filtration $(\mathrm{I} \text { trab/5-FU) })^{\S}$} & 3 \\
\hline \multicolumn{2}{|c|}{ Repeat filtration (I trab/MMC) } & 4 \\
\hline \multicolumn{2}{|c|}{ Repeat filtration ( 2 or more trab) $)^{\S}$} & 4 \\
\hline \multicolumn{2}{|c|}{$\begin{array}{l}\mathrm{PCIOL}^{*} \text { with virgin conjunctiva in I or } 2 \\
\text { superior quadrants }\end{array}$} & I \\
\hline \multicolumn{2}{|c|}{$\mathrm{PClOL}^{*}$ with scar in superior quadrants } & 2 \\
\hline \multicolumn{2}{|c|}{$\mathrm{AClOL}^{\dagger}$ without vitreous in the $\mathrm{AC}^{\ddagger}$} & 2 \\
\hline \multicolumn{2}{|c|}{$\mathrm{AClOL}^{\dagger}$ with vitreous in the $\mathrm{AC}^{\ddagger}$} & 3 \\
\hline \multicolumn{2}{|l|}{ Aphakia } & 3 \\
\hline \multicolumn{2}{|c|}{ Other surgery with conjunctival scarring } & 1 \\
\hline Score $\pi$ & Concentration & Exposure time $^{* *}$ \\
\hline I to 2 & $0.2 \mathrm{mg} / \mathrm{ml}$ & $\mathrm{I}-2$ minutes \\
\hline 3 to 4 & $0.3 \mathrm{mg} / \mathrm{ml}$ & $3-4$ minutes \\
\hline 5 and over & $0.4 \mathrm{mg} / \mathrm{ml}$ & $5-6$ minutes \\
\hline
\end{tabular}

Notes: "PCIOL, posterior chamber intraocular lens; ${ }^{\dagger} \mathrm{ACIOL}$, anterior chamber

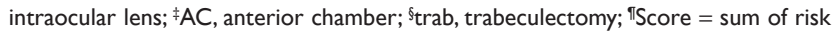
factor values; ${ }^{*}$ Actual exposure times were adjusted at the time of surgery according to bleeding, scar tissue and thickness of Tenon capsule.
A standard trabeculectomy with a limbal-based conjunctival flap was performed for all patients. A $5 \times 7 \mathrm{~mm}$ block of polyvinyl acetal sponge, soaked in the predetermined concentration of $\mathrm{MMC}$, was placed on the sclera near the limbus, prior to developing the scleral flap, and the conjunctival-Tenon capsule flap was draped over the sponge. If the duration of MMC exposure exceeded two minutes, a new sponge was used for every additional two minutes. After removing the last sponge, the exposed tissues were copiously irrigated with balanced salt solution.

Preoperative data collected on each patient included age, ethnicity, type of glaucoma, intraocular pressure (IOP), glaucoma medications, and previous laser or incisional surgery. The data collected on each follow-up visit included IOP by Goldmann applanation tonometry with correction for central corneal thickness and glaucoma medications. The minimum postoperative follow-up was 6 months. Outcome was based on the IOP of the last follow-up visit or prior to additional glaucoma surgery.

Success was arbitrarily defined as a final IOP between 7 and $17 \mathrm{mmHg}$ with or without the need for glaucoma medication, while eyes with an IOP under $7 \mathrm{mmHg}$ were defined as hypotony, and those over $17 \mathrm{mmHg}$ or those that underwent additional glaucoma surgery were defined as hypertension. The patients were divided according to success, hypotony or hypertension outcome. The hypotony and hypertension groups were each compared to the success group for statistical differences with regard to MMC concentration and exposure time, as well as age, gender, ethnicity, glaucoma type, preoperative IOP and prior surgery, using the proportional hazard Cox regression model for multivariate analysis.

\section{Results}

A total of 155 eyes of 155 consecutive patients who underwent trabeculectomy with adjunctive MMC were included in the study. Patient characteristics and preoperative data are shown in Table 2. The mean patient age was 65.4 years (range, 18-89 years) and eighty-five (54.8\%) were female. Thirty-two patients $(20.6 \%)$ were black and $123(79.4 \%)$ were nonblack. One hundred and twenty nine patients $(83.2 \%)$ had chronic open-angle glaucoma, and the other forms of glaucoma included $8(5.2 \%)$ chronic angle-closure, $9(5.8 \%)$ pseudoexfoliation, 3 (1.9\%) uveitic, 2 (1.3\%) juvenile, and 4 (2.6\%) miscellaneous types. Of the 155 eyes, $62(40.0 \%)$ had undergone prior argon laser trabeculoplasty and $44(28.4 \%)$ had previous failed trabeculectomy. Cataract 
Table 2 Patient characteristics and preoperative data of total study population

\begin{tabular}{|c|c|}
\hline Variable & Total \\
\hline \multicolumn{2}{|l|}{ Age (years) } \\
\hline mean $\pm S D^{*}$ & $65.36 \pm 15.40$ \\
\hline range & 18 to 89 \\
\hline \multicolumn{2}{|l|}{ Gender } \\
\hline male & $70(45.2 \%)$ \\
\hline female & $85(54.8 \%)$ \\
\hline \multicolumn{2}{|l|}{ Ethnicity } \\
\hline black & $32(20.6 \%)$ \\
\hline nonblack & $123(79.4 \%)$ \\
\hline \multicolumn{2}{|l|}{ Glaucoma type } \\
\hline $\mathrm{COAG}^{\dagger}$ & $129(83.2 \%)$ \\
\hline other & $26(16.8 \%)$ \\
\hline \multicolumn{2}{|l|}{ Previous surgery } \\
\hline trabeculectomy & $44(28.4 \%)$ \\
\hline $\mathrm{ALT}^{\ddagger}$ & $62(40.0 \%)$ \\
\hline cataract & $43(27.7 \%)$ \\
\hline \multicolumn{2}{|c|}{ Preoperative IOP§ (mmHg) } \\
\hline mean $\pm \mathrm{SD}^{*}$ & $24.02 \pm 8.98$ \\
\hline range & 10 to 65 \\
\hline \multicolumn{2}{|c|}{ Preoperative medications } \\
\hline $0-2$ & $74(47.7 \%)$ \\
\hline 3 or more & $8 \mathrm{I}(52.3 \%)$ \\
\hline
\end{tabular}

Notes: "SD, standard deviation; ${ }^{\mathrm{t} C O A G}$, chronic open-angle glaucoma; ${ }^{\mathrm{A} A L T}$, argon laser trabeculoplasty; $\$ \mid \mathrm{OP}$, intraocular pressure.

extraction had been previously performed in the study eye of $43(27.7 \%)$ patients. The mean preoperative IOP was $24.0 \pm 9.0 \mathrm{mmHg}$ and 81 patients $(52.3 \%)$ were on 3 or more medications in the study eye. The mean follow-up was 15.1 months with a range of 6 to 31 months.

The mean final IOP for all patients was $12.6 \pm 6.1 \mathrm{mmHg}$, with $119(76.8 \%)$ classified as success, $21(13.5 \%)$ as hypertension and $15(9.7 \%)$ as hypotony. The preoperative and surgical data for the success, hypotony, and hypertension groups are summarized in Table 3 , and the postoperative data are summarized in Table 4.

Of the 119 patients who were defined as having a successful outcome, the mean preoperative IOP was $23.2 \pm 9.2 \mathrm{mmHg}$ and 63 patients $(52.9 \%)$ were on 3 or more medications in the study eye. The mean final IOP in this outcome group was $11.7 \pm 2.9 \mathrm{mmHg}$, and $8(6.7 \%)$ required 3 or more medications postoperatively. Of the 21 patients in the hypertension group, the mean preoperative IOP was $29.1 \pm 7.1 \mathrm{mmHg}$ and 12 patients (57.1\%) were on 3 or more medications. The mean final IOP was $23.6 \pm 7.1 \mathrm{mmHg}$ and all were on maximum tolerable medical therapy. Of the 15 patients in the hypotony group, the mean preoperative IOP was $23.4 \pm 7.7 \mathrm{mmHg}$, and 6 patients $(40.0 \%)$ were on 3 or more medications. The mean final IOP was $4.4 \pm 1.5 \mathrm{mmHg}$, with no patients receiving medical therapy. Outcomes were not influenced by the presence or type of cataract surgery nor by the refractive status of the patients.

Multivariate analysis, comparing the success and hypotony groups, revealed no statistically significant difference with regard to MMC concentration or exposure time, gender, ethnicity, glaucoma type, preoperative IOP, or previous surgery. However, there was a statistically significant difference with regard to age, in that the mean age of the hypotony group was $73.5 \pm 6.1$ years compared to $65.6 \pm 15.2$ years in the success group $(p=0.009)$.

The analysis comparing the success and hypertension groups revealed no statistically significant difference with regard to MMC protocol or any patient variables.

\section{Discussion}

In 1983, Chen ${ }^{1}$ was the first to report the clinical use of intraoperative $\mathrm{MMC}$ as an adjunct to glaucoma filtering surgery. Although subsequent studies have supported the beneficial effects of MMC on postoperative IOP reduction and filtration bleb survival, the benefit has been tempered by associated complications, including hypotony maculopathy. There is a considerable body of literature addressing the quest for a protocol that best balances the benefits and risks of intraoperative MMC as an adjunct to trabeculectomy, a portion of which is summarized in Table 5 .

An important question in this search for the ideal protocol has been whether a single protocol is suitable for all patients, or whether the protocol should be titrated for individual patients. The two variables that have received the most attention in evaluating protocols are concentration and exposure time of the MMC. Early studies used fixed concentrations of $0.2-0.5 \mathrm{mg} / \mathrm{ml}$ for $3-5$ minute exposures and revealed uniformly high success rates with regard to IOP control and low rates of hypotony. ${ }^{1,3-7}$ Although these studies were primarily in patients who were at high risk of failure due to excessive fibrosis, other investigators have performed initial trabeculectomies in lower risk patients, using similar, fixed protocols to those described above, and also reported high success with low rates of hypotony. ${ }^{8,9}$

In some studies, different concentrations of MMC were arbitrarily assigned to patients, while the exposure time was kept constant in all patients. ${ }^{2,17-18}$ In each study, patients 
Table 3 Comparison of preoperative and surgical data for hypertension and hypotony outcome groups against success group

\begin{tabular}{|c|c|c|c|c|c|}
\hline Variable & Success* & Hypertension $^{\dagger}$ & p value & Hypotony $\ddagger$ & p value \\
\hline No of eyes & 119 & 21 & & 15 & \\
\hline Age (years) & & & 0.132 & & 0.009 \\
\hline mean $\pm \mathrm{SD}^{\S}$ & $65.62 \pm 15.24$ & $58.05 \pm 17.95$ & & $73.53 \pm 6.16$ & \\
\hline range & 18 to 89 & 19 to 82 & & 61 to 82 & \\
\hline Gender $\S$ & & & 0.376 & & 0.239 \\
\hline male & $56(47.1 \%)$ & 7 (33.3\%) & & 7 (46.7\%) & \\
\hline female & $63(52.9 \%)$ & $14(66.7 \%)$ & & $8(53.3 \%)$ & \\
\hline Ethnicity§ & & & 0.828 & & 0.156 \\
\hline black & $26(21.8 \%)$ & $5(23.8 \%)$ & & I (6.7\%) & \\
\hline non-black & $93(78.2 \%)$ & $16(76.2 \%)$ & & 14 (93.3\%) & \\
\hline Glaucoma type ${ }^{\S}$ & & & 0.168 & & 0.597 \\
\hline COAG ${ }^{\dagger \dagger}$ & 102 (85.7\%) & 15 (7I.4\%) & & $12(80.0 \%)$ & \\
\hline other & $17(14.3 \%)$ & $6(28.6 \%)$ & & $3(20.0 \%)$ & \\
\hline Previous surgery" & & & 0.164 & & 0.179 \\
\hline trabeculectomy & $32(26.9 \%)$ & $6(28.6 \%)$ & & $6(40.0 \%)$ & \\
\hline $\mathrm{ALT}^{\ddagger \ddagger}$ & $46(38.7 \%)$ & $8(38.1 \%)$ & & 7 (46.7\%) & \\
\hline cataract & $30(25.2 \%)$ & $8(38.1 \%)$ & & $5(33.3 \%)$ & \\
\hline Preoperative IOP\$§ $(\mathrm{mmHg})$ & & & 0.280 & & 0.595 \\
\hline mean $\pm S D^{* *}$ & $23.20 \pm 9.19$ & $29.10 \pm 7.08$ & & $23.40 \pm 7.67$ & \\
\hline range & 10 to 65 & 19 to 48 & & 15 to 44 & \\
\hline Preoperative medications ${ }^{*}$ & & & 0.120 & & 0.451 \\
\hline $0-2$ & $56(47.1 \%)$ & $9(42.9 \%)$ & & $9(60.0 \%)$ & \\
\hline 3 or more & $63(52.9 \%)$ & $12(57.1 \%)$ & & $6(40.0 \%)$ & \\
\hline $\begin{array}{l}\text { MMC concentration } \\
(\mathrm{mg} / \mathrm{ml})\end{array}$ & & & 0.443 & & 0.185 \\
\hline mean $\pm S D^{* *}$ & $0.25 \pm 0.08$ & $0.28 \pm 0.09$ & & $0.29 \pm 0.08$ & \\
\hline range & 0.2 to 0.4 & 0.2 to 0.4 & & 0.2 to 0.4 & \\
\hline MMC duration (minutes) & & & 0.891 & & 0.085 \\
\hline mean $\pm S D^{* *}$ & $2.69 \pm 0.84$ & $2.88 \pm 1.04$ & & $3.03 \pm 0.88$ & \\
\hline range & I to 5 & 2 to 5 & & I to 4 & \\
\hline
\end{tabular}

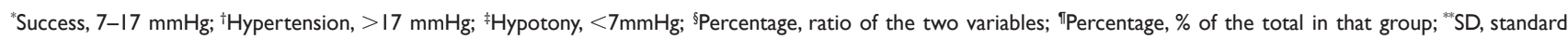
deviation; ${ }^{\dagger+}$ COAG, chronic open-angle glaucoma; ${ }^{\ddagger} A L T$, argon laser trabeculoplasty; ${ }^{\S \S} \mid O P$, intraocular pressure.

receiving the higher concentration were more likely to develop hypotony.

Other studies have examined the impact of variable exposure times with MMC. An in vitro study by Jampe ${ }^{19}$ showed that a 1-minute exposure of MMC may be as effective as a 5-minute exposure for inhibition of Tenon's fibroblast proliferation. In clinical trials, in which a fixed concentration of MMC was titrated from 0.5 to 5 minutes exposure time, according to individual patient's risk factors for failure from excessive fibrosis, some studies also revealed no correlation with exposure time and either success of IOP control or risk of hypotony, ${ }^{10,11,20}$ while others showed a higher incidence of hypotony in eyes receiving the longer exposure time. ${ }^{21,22}$
In two clinical trials, the MMC concentration was kept constant at 0.3 or $0.4 \mathrm{mg} / \mathrm{ml}$, and the exposure time was titrated between 2-3 minutes or 4-5 minutes, based on risk factors for surgical failure. ${ }^{12,13}$ In both series, hypotony maculopathy occurred more in the lower risk patients, who received the shorter duration of exposure. The authors interpreted these findings to suggest that individual patient factors had a greater influence on the outcome than the exposure time of the MMC.

Other investigators have varied both concentration and exposure time according to risk of surgical failure, as was utilized in the present study. In two of these studies, which compared $0.5 \mathrm{mg} / \mathrm{ml}$ for 5 minutes with $0.4 \mathrm{mg} / \mathrm{ml}$ for 3 minutes $^{14}$ and $0.2-0.5 \mathrm{mg} / \mathrm{ml}$ for $0.5-5$ minutes,${ }^{15}$ neither study revealed 
Table 4 Comparison of postoperative data for hypertension and hypotony groups against success group

\begin{tabular}{|c|c|c|c|}
\hline Variable & Success* & Hypertension ${ }^{\dagger}$ & Hypotony $\ddagger$ \\
\hline \multicolumn{4}{|c|}{ Final IOPף $(\mathrm{mmHg})$} \\
\hline mean $\pm \mathrm{SD}^{\S}$ & $11.65 \pm 2.86$ & $23.57 \pm 7.10$ & $4.40 \pm 1.45$ \\
\hline range & 7 to 17 & 18 to 48 & I to 6 \\
\hline \multicolumn{4}{|l|}{$\begin{array}{l}\text { Postoperative } \\
\text { medications }{ }^{* * *}\end{array}$} \\
\hline $0-2$ & III (93.3\%) & 17 (81.0\%) & 0 \\
\hline 3 or more & $8(6.7 \%)$ & $4(19.0 \%)$ & 0 \\
\hline $\begin{array}{l}\text { Mean follow-up } \\
\text { (mos) }\end{array}$ & $15.21 \pm 7.10$ & $14.33 \pm 6.28$ & $15.07 \pm 6.60$ \\
\hline range & 6 to 31 & 6 to 27 & 6 to 30 \\
\hline
\end{tabular}

Notes: 'Success, 7-17 mmHg; †Hypertension, $>17 \mathrm{mmHg}$; ${ }^{\prime}$ Hypotony, $<7 \mathrm{mmHg}$; $\$ \mathrm{SD}$, standard deviation;"IOP, intraocular pressure; "Percentage, ratio of the two variables.

a correlation between MMC variables and IOP outcome. A third study compared protocols of $0.2 \mathrm{mg} / \mathrm{ml}$ for 2 minutes, $0.2 \mathrm{mg} / \mathrm{ml}$ for 4 minutes, $0.4 \mathrm{mg} / \mathrm{ml}$ for 2 minutes, or no MMC and found a possible dose-response relationship, with exposure time appearing to be more important than concentration. ${ }^{16}$

In the present study, we divided patients into three outcome groups: success (IOP of $7-17 \mathrm{mmHg}$ with or without glaucoma medication); hypotony (IOP less than $7 \mathrm{mmHg}$ ); and hypertension (IOP greater than $17 \mathrm{mmHg}$ or requiring further glaucoma surgery), and examined whether either MMC variable or certain patient variables correlated with the outcome groups. The only significant variable was age, with the hypotony group having an older mean age than the success group. This finding is consistent with prior observations that younger patients are generally at greater risk of filtration surgery failure, ${ }^{23}$ and suggests that older patients require less, if any, MMC during trabeculectomy. On the other hand, younger patients are also at greater risk of developing maculopathy from hypotony, ${ }^{24,25}$ making it difficult to select the optimum MMC protocol, especially in young patients.

The clinical investigations cited in this paper, including our study, do not provide clear support for the superiority of a titration protocol for MMC as an adjunct to trabeculectomy, compared to a fixed protocol for all patients. While some studies suggest that higher concentrations and/or longer exposure times may increase the success of IOP control, but also increase the risk of hypotony, ${ }^{2,17,18}$ the majority of studies show no correlation between either MMC variable and the surgical outcome. There may be several explanations for the latter observation.

First, some studies only included patients who were at high risk of failure from excessive fibrosis, so that a single, fixed protocol might have been appropriate for the majority of these patients. In those studies in which the patient population represented a wider range of risk for surgical failure, and MMC variables were titrated, as in the present study, the lack of correlation between MMC variables and surgical outcome might be interpreted to suggest that other patient variables were responsible for the hypertension and hypotony outcomes. In other words, with a less appropriate MMC protocol, the concentration or exposure time might have been significantly higher in the hypotony group and lower in the hypertension group. It is just as likely, however, that the lack of correlation between MMC protocol and IOP outcome represents an inappropriate combination of all the surgical and patient variables.

Our study is limited by the retrospective study design. In addition, it is difficult to extrapolate our results to that of others, because of many variations in surgical technique. For example, while we applied MMC before development of the scleral flap, other surgeons apply the MMC beneath the scleral flap. These and other variations in surgical technique could influence the outcome of trabeculectomy beyond the influence of the concentration and duration of MMC application.

It seems most reasonable to conclude from the studies cited in this paper that the IOP outcome following trabeculectomy with adjunctive MMC represents a complex interaction of many surgical and patient variables. In addition to the concentration and exposure time of $\mathrm{MMC}$, the vehicle used to deliver the MMC and the surgical placement of the vehicle, as well as all the other steps in the operation, may well influence the outcome. There may also be patient variables, beyond those evaluated in the present study, such as the thickness of Tenon's capsule, the degree of vascularity and bleeding, and possibly different receptor responses to $\mathrm{MMC}$, that exert an influence on the surgical outcome.

While no claims can be made for the superiority of any specific MMC protocol in overcoming this complex problem, the findings in the present study and a review of the literature are felt to support the merit of carefully evaluating the risk factors of each individual patient and selecting the surgical approach, including the use of antifibrotic agents, that is felt to be most appropriate for that patient.

\section{Disclosure}

This study was presented as a poster at the American Ophthalmologic Society Annual Meeting, Half Moon Bay, California, May 21-24, 2006. This study was performed at the Department of Ophthalmology and Visual Science, Yale University School of Medicine, 
Table 5 Summary of literature evaluating mitomycin C (MMC) as an adjunct to trabeculectomy

\begin{tabular}{|c|c|c|c|c|c|c|}
\hline \multirow[t]{2}{*}{ Authors } & \multirow[t]{2}{*}{ Number of eyes } & \multirow{2}{*}{$\begin{array}{l}\text { Duration of follow-up } \\
\text { (months) }\end{array}$} & \multirow{2}{*}{$\begin{array}{l}\text { MMC concentration } \\
(\mathrm{mg} / \mathrm{ml})\end{array}$} & \multirow{2}{*}{$\begin{array}{l}\text { MMC duration } \\
\text { (minutes) }\end{array}$} & \multicolumn{2}{|l|}{ Results } \\
\hline & & & & & Success & $\begin{array}{l}\text { Hypotony } \\
\text { (eyes) }\end{array}$ \\
\hline Kitazawa et al I99I & 17 & 7 to 12 & 0.2 & 5 & $88 \%$ & 0 \\
\hline Skuta et al 1992 & 20 & 6 & 0.5 & 5 & $95 \%$ & 1 \\
\hline Katz et al 1995 & 20 & 26 to 38 & 0.5 & 5 & $81.3 \%$ & I \\
\hline Palmer I99I & 33 & 6 to 42 & 0.2 & 5 & $84 \%$ & 1 \\
\hline El Sayyad et al 2000 & 68 & 12 & 0.3 & 3 & $71 \%-82 \%$ & 4 \\
\hline Nuijts et al 1997 & 25 & 12 & 0.2 & 5 & $92 \%$ & 1 \\
\hline Scott et al 1998 & 89 & 24 & 0.5 & 5 & $85 \%$ & 4 \\
\hline \multirow[t]{2}{*}{ Kitazawa et al 1993} & 22 & 6 to 17 & a) 0.2 & a) 5 & $100 \%$ & 2 \\
\hline & & & b) 0.02 & b) 5 & $63.6 \%$ & 0 \\
\hline \multirow[t]{2}{*}{ Sanders et al 1999} & 50 & 12 & a) 0.2 & a) 2 & $72.0 \%$ & 2 \\
\hline & & & b) 0.4 & b) 2 & $70.8 \%$ & 3 \\
\hline Chen et al 1990 & 59 & 12 to 76 & $0.1-0.4$ & 5 & $77.8 \%$ & 2 \\
\hline \multirow[t]{2}{*}{ Cohen et al 1997} & 106 & 14 & a) 0.5 & a) $0.5-1$ & $*$ & 1 \\
\hline & & & b) 0.5 & b) $1-3$ & & 4 \\
\hline Perkins et al 1998 & 68 & 36 & 0.5 & $0.5-5$ & $*$ & 3 \\
\hline \multirow[t]{2}{*}{ Shields et al 1993} & 59 & 2 to 14 & a) 0.4 & a) $2-3$ & $91.2 \%$ & 4 \\
\hline & & & b) 0.4 & b) 4-5 & $72.2 \%$ & 0 \\
\hline \multirow[t]{2}{*}{ Stone et al 1998} & 57 & 11.9 & a) 0.3 & a) $1-3$ & $*$ & 3 \\
\hline & & & b) 0.3 & b) 4-5 & & 0 \\
\hline \multirow{2}{*}{$\begin{array}{l}\text { Megevand et al } \\
1995\end{array}$} & 73 & 18 & a) 0.2 & a) 2 & $88 \%$ & 2 \\
\hline & & & b) 0.2 & b) 5 & $84 \%$ & 1 \\
\hline \multirow[t]{2}{*}{ Kim et al 1998} & 88 & 3 to 12 & a) 0.5 & a) $0.5-1$ & $\dagger$ & 29 \\
\hline & & & b) 0.5 & b) $3-5$ & & 20 \\
\hline Zacharia et al 1993 & 52 & 2 to 12 & 0.4 & $3.5-7$ & $\dagger$ & 17 \\
\hline \multirow{3}{*}{$\begin{array}{l}\text { Neelakantan et al } \\
1994\end{array}$} & 93 & & a) 0.4 & a) 3 & $*$ & \\
\hline & & & & & & \\
\hline & & & b) 0.5 & b) 5 & & \\
\hline Cheung et al 1997 & 157 & 36 & $0.2-0.5$ & $0.5-5$ & * & \\
\hline \multirow[t]{3}{*}{ Robin et al 1997} & 300 & 12 & a) 0.2 & a) 2 & $79.4 \%$ & 2 \\
\hline & & & b) 0.2 & b) 4 & $83.3 \%$ & 2 \\
\hline & & & c) 0.4 & c) 2 & $85.7 \%$ & 2 \\
\hline
\end{tabular}

Notes: "No correlation between MMC variable and outcome; ‘Statistically significant association between MMC variable and outcome.

New Haven, Connecticut 06520, USA. Study supported in part by unrestricted grants from Research to Prevent Blindness (645 Madison Avenue, NY, NY 10022-1010) and Connecticut Lions Eye Research Foundation (P.O. Box 9268, New Haven, CT 06533). The authors report no conflicts of interest in this work.

\section{References}

1. Chen CW. Enhanced intraocular pressure controlling effectiveness of trabeculectomy by local application of mitomycin C. Trans Asia Pac Acad Ophthalmol. 1983;9:172-7.

2. Chen CW, Huang HT, Bair JS, et al. Trabeculectomy with simultaneous topical application of mitomycin-C in refractory glaucoma. $\mathrm{J} \mathrm{Ocul}$ Pharmacol. 1990;6:175-82.
3. Kitazawa Y, Kawase K, Matsushita H, et al. Trabeculectomy with mitomycin: a comparative study with fluorouracil. Arch Ophthalmol. 1991;109:1693-8.

4. Skuta GL, Beeson CC, Higginotham EJ, et al. Intraoperative mitomycin versus postoperative 5-fluorouracil in high-risk glaucoma filtering surgery. Ophthalmology. 1992;99:438-44.

5. Katz GJ, Higginbotham EJ, Lichter PR, et al. Mitomycin C versus 5-Fluorouracil in high-risk glaucoma filtering surgery. Ophthalmology. 1995;103:1263-9.

6. Palmer SS. Mitomycin as adjunct chemotherapy with trabeculectomy. Ophthalmology. 1991;98:317-21.

7. El Sayyad F, Belmekki M, Helal M, et al. Simultaneous subconjunctival and subscleral mitomycin-C application in trabeculectomy. Ophthalmology. 2000;107:298-302.

8. Nuijts RM, Vernimmen RCJ, Webers CA. Mitomycin C primary trabeculectomy in primary glaucoma of white patients. J Glaucoma. 1997:6:293-7. 
9. Scott IU, Greenfield DS, Schiffman J, et al. Outcomes of primary trabeculectomy with the use of adjunctive mitomycin. Arch Ophthalmol. 1998;116:286-91.

10. Cohen JS, Novack GD, Li ZL. The role of mitomycin treatment duration and previous intraocular surgery on the success of trabeculectomy surgery. J Glaucoma. 1997;6:3-9.

11. Perkins TW, Gangnon R, Ladd W, et al. Trabeculectomy with mitomycin C: intermediate-term results. J Glaucoma. 1998;7:230-6.

12. Shields MB, Scroggs MW, Sloop CM, et al. Clinical and histopathologic observations concerning hypotony after trabeculectomy with adjunctive mitomycin C. Am J Ophthalmol. 1993;116:673-83.

13. Stone RT, Herndon LW, Allingham RR, et al. Results of trabeculectomy with $0.3 \mathrm{mg} / \mathrm{ml}$ mitomycin $\mathrm{C}$ titrating exposure times based on risk factors for failure. J Glaucoma. 1998;7:39-44.

14. Neelakantan A, Rao BS, Vijaya L, et al. Effect of the concentration and duration of application of mitomycin $\mathrm{C}$ in trabeculectomy. Ophthalmic Surg. 1994;25:612-615.

15. Cheung JC, Wright MM, Murali S, et al. Intermediate-term outcome of variable dose mitomycin C filtering surgery. Ophthalmology. 1997;104:143-9.

16. Robin AL, Ramakrishnan R, Krishnadas R, et al. A long-term doseresponse study of mitomycin in glaucoma filtration surgery. Arch Ophthalmol. 1997;115:969-73.

17. Kitazawa Y, Suemori-Matsushita H, Yamamoto T, et al. Low-dose and high-dose mitomycin trabeculectomy as an initial surgery in primary open-angle glaucoma. Ophthalmology. 1993;100:1624-8.
18. Sanders SP, Cantor LB, Dobler AA, et al. Mitomycin C in higher risk trabeculectomy: a prospective comparison of $0.2-$ to $0.4-\mathrm{mg} / \mathrm{cc}$ doses. J Glaucoma. 1999;8:193-8.

19. Jampel HD. Effect of brief exposure to mitomycin $\mathrm{C}$ on viability and proliferation of cultured human Tenon's capsule fibroblasts Ophthalmology. 1992;99:1471-6.

20. Megevand GS, Salmon JF, Scholtz RP, et al. The effect of reducing the exposure time of mitomycin $\mathrm{C}$ in glaucoma filtering surgery. Ophthalmology. 1995;102:84-90.

21. Kim YY, Sexton RM, Shin DH, et al. Outcomes of primary phakic trabeculectomies without versus with 0.5 - to 1-minute versus 3 - to 5-minute mitomycin C. Am J Ophthalmol. 1998;126:755-62.

22. Zacharia PT, Deppermann SR, Schuman JS. Ocular hypotony after trabeculectomy with mitomycin C. Am J Ophthalmol. (93);116:314-26.

23. Sturmer J, Broadway DC, Hitchings RA. Young patient trabeculectomy: assessment of risk factors for failure. Ophthalmology. 1993;100:928-39.

24. Stamper RL, McMenemy MG, Lieberman MF. Hypotonous maculopathy after trabeculectomy with subconjunctival 5-fluorouracil. Am J Ophthalmol. 1992;114:544-53.

25. Fannin LA, Schiffman JC, Budenz DL. Risk factors for hypotony maculopathy. Ophthalmology. 2003;110:1185-91. 
